\title{
Percutaneous release of trigger finger: An easy and safe procedure
}

\author{
Pawan Rawat ${ }^{1}$, Kunal $\mathrm{Vij}^{2, *}$ \\ ${ }^{1,2}$ Assistant Professor Dept. of Orthopaedics, Sri Guru Ram Rai Medical College, Dehradun, Uttarakhand, India
}

*Corresponding Author:

Email: drkunalvij@yahoo.in

\begin{abstract}
Introduction: Trigger finger is caused by irritation of the flexor tendon as it slides through the fibro-osseous sheath. Its surgical options include open and percutaneous minimally invasive methods.

Aim: This study is aimed at elucidating the efficacy of percutaneous release of trigger finger.

Materials and Methods: This is a prospective study carried out in our institution Shri Guru Ram Rai Medical College Dehradun, India over a period of 2 years from June 2015 to august 2017. This study includes 68 trigger finger and thumb of 58 patients between 28 to 64 years. Here percutaneous trigger finger release of A1 pulley was done with the help of $18 \mathrm{G}$ hypodermic needle under local anaesthetic cover as a day care procedure. Subsequently the patient was followed up at least for 3 months.

Results: Symptoms were resolved completely in all patients. None had any serious complication. Only a few patients had minor temporary wound related complicationsand temporary stiffness.

Conclusions: Percutaneous release of trigger finger is effective, convenient, cost effective day care surgery without any significant complications in skilled hands.
\end{abstract}

Keywords: Trigger finger, Percutaneous release.

\section{Introduction}

Trigger finger or trigger digit is a very common stenosing tenosynovitis causing disability of the fingers characterized by pain, snapping, catching, locking or even flexion contracture of the involved digit. ${ }^{1}$ It is basically due to mismatch in the diameter of the flexor tendon and the fibro-osseous canal and its pulley system. The primary pathology is in A1 pulley at the level of head of metacarpal. This condition can be treated either by conservative methods or by surgical methods. Surgical options include percutaneous release or open release in case of failure of conservative methods. ${ }^{2-5}$

Percutaneous release is increasingly becoming popular and the method of choice among orthopaedic surgeons for being cost effective, convenient, day care surgery with no need for hospitalization. It has no significant complications and post op morbidity with high patient satisfaction and early return to work. ${ }^{6-7}$ In present study, we performed percutaneous release of A1 pulley as by Eastwood ${ }^{6}$ with $18 \mathrm{G}$ needle under local anaesthetic in aseptic conditions in minor OT and followed the patient at least for 3 months. The outcomes were recorded in terms of relief of symptoms, patient satisfaction, ROM, complications and resumption of work.

\section{Materials and Methods}

In this prospective study, we included 68 trigger digits of 58 patients (40 females, 18 males) of age group 28-64 years. Diagnosis is made clinically. Usually patients present as locking or with pain and nodular swelling on palpation at MP joint which moves with finger movement. No investigation is required. All these patients underwent percutaneous release with the help of $18 \mathrm{G}$ needle in aseptic conditions in minor OT. The patient was put on anti-inflammatory drug (Aceclofenac $50 \mathrm{mg}+$ paracetamol $325 \mathrm{mg}$ combination) twice a day per oral for 3 days along with local application of ice. The patients were followed up on day 7 , one month and 3 month.

The outcome was assessed by-1) level of satisfaction (very satisfactory, Satisfactory, unsatisfactory), 2) complications, 3) Days to resume work, 4) Range of motion.

Satisfactory and very satisfactory response was considered as favorable outcome.

The technique of percutaneous release: After taking properly informed consent, patient was taken to minor OT. The procedure was performed under aseptic conditions as day care procedure. The release was done under local anaesthetic using $18 \mathrm{G}$ needle. The hand was painted and draped. One- $2 \mathrm{ml}$ of $2 \%$ lignocaine injected around at the site of knot over head of metacarpal. 18G needle inserted over the knot with bevel of the needle parallel to the tendon till it reaches the flexor tendon (Fig. 1). Proper position inside tendon is confirmed by paradoxical movement of the needle on active flexion of the digit. Now the needle is slightly withdrawn just out of the tendon and then moved backwards and forwards feeling the grating sensation of the fibro-osseous pulley till there is none. The release is further confirmed by no more feeling of triggering/ catching sensation by the patient on active flexion and extension of the digit. It's a day care procedure and immediate unlocking, increase in ROM and subsidence of pain confirm s the clinical diagnosis. 


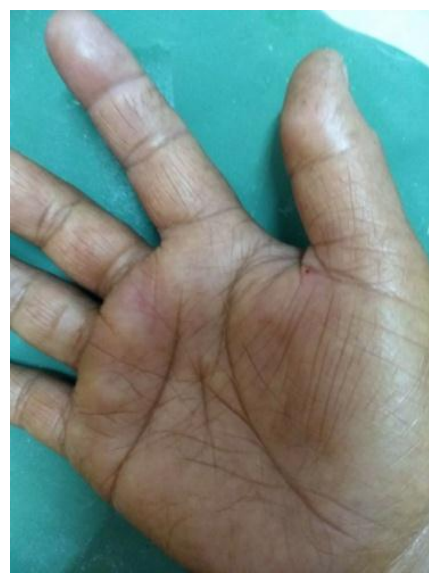

Pre-Operative

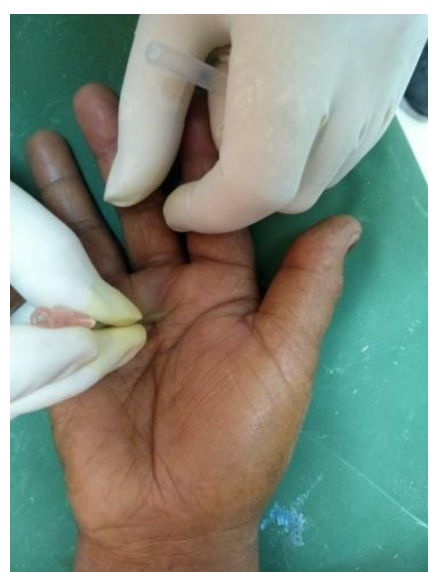

Intra-Operative

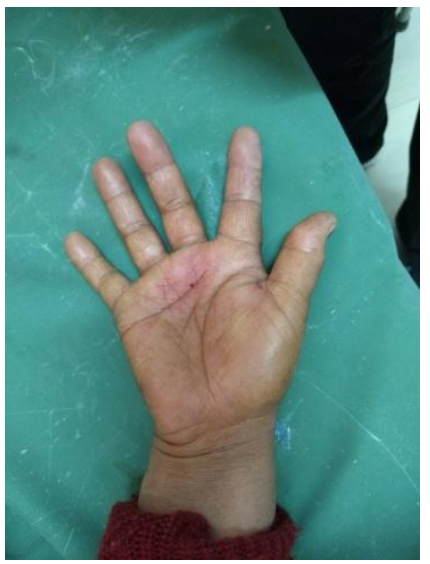

Post-Operative

Fig. 1:

Table 1: Patient presentation

\begin{tabular}{|l|c|}
\hline Clinical feature & Number of digits $\mathbf{( \% )}$ \\
\hline Symptoms at presentation & \\
1. Pain with nodular s welling- & $6(8.82 \%)$ \\
2. Catching/Snapping/Locking- & $62(91.17 \%)$ \\
3. Contracture - & 0 \\
\hline
\end{tabular}

Table 2: Patient information

\begin{tabular}{|l|c|}
\hline \multicolumn{1}{|c|}{ Patient Characteristic } & Number (\%) \\
\hline Mean age(years) & 41 \\
Male/ female & $18 / 40(31.03 \% / 68.96 \%)$ \\
Dominant/ Non Dominant hand & $41 / 27(60.29 \% / 39.70 \%)$ \\
Digit involved & \\
1. Thumb & $26(38.23 \%)$ \\
2. Index & $28(41.17 \%)$ \\
3. Middle & $10(14.70 \%)$ \\
4. Ring & $4(5.88 \%)$ \\
\hline
\end{tabular}

Table 3: Trigger finger grading (Quinnell's Grading) [18]

\begin{tabular}{|l|c|}
\hline Grade: & Number (\%) \\
\hline Grade-1 & $6(8.82 \%)$ \\
Pain and nodularity & $24(35.29 \%)$ \\
\hline Grade-2 & \\
Self-correctable triggering & $38(55.88 \%)$ \\
\hline $\begin{array}{l}\text { Grade-3 } \\
\text { Manually correctable triggering }\end{array}$ & 0 \\
\hline $\begin{array}{l}\text { Grade-4 } \\
\text { Irreducible / Contracture }\end{array}$ \\
\hline
\end{tabular}

Table 4: Patient outcomes

\begin{tabular}{|l|c|c|c|}
\hline Outcome & Day 7 & 1 Month & 3 Month \\
\hline Objective outcome & & & \\
1. Satisfactory & $68(100 \%)$ & $68(100 \%)$ & $68(100 \%)$ \\
2. Unsatisfactory & 0 & 0 & 0 \\
\hline Subjective outcome & & & $57(83.82 \%)$ \\
1. Very satisfactory & $35(51.47 \%)$ & & $11(16.17 \%)$ \\
2. Satisfactory & $33(48.52 \%)$ & & 0 \\
3. Unsatisfactory & 0 & 0 & 0 \\
\hline Complications & & & \\
1. Pain & $7(10.29 \%)$ & 0 & \\
\hline
\end{tabular}




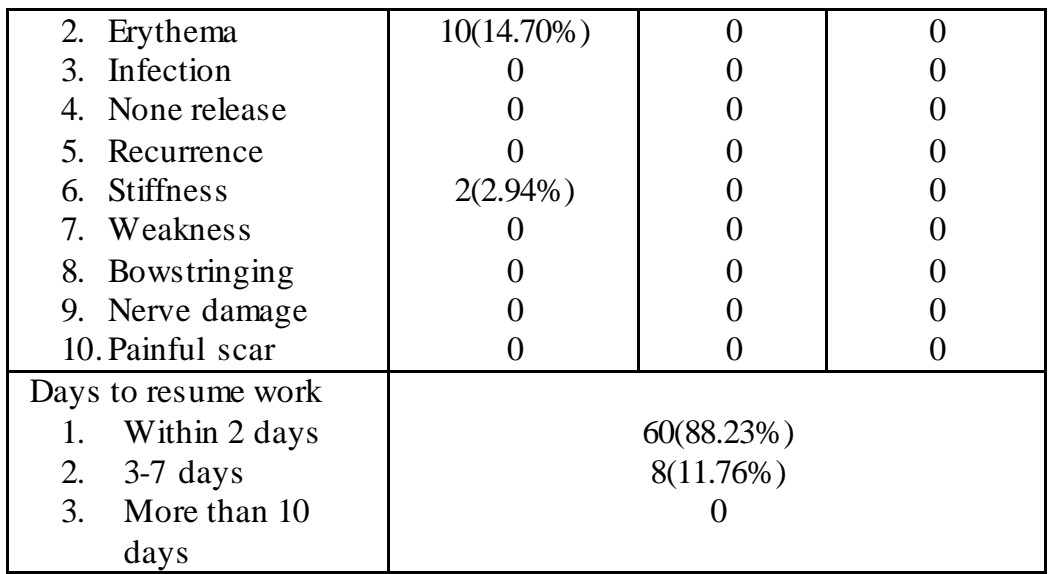

\section{Results}

All the percutaneous release went uneventful and no significant complications were encountered in any patients. All trigger finger patients were relieved of triggering/ catching instantly and of pain in average 7 days (3-10 days). Average time of resumption of work was 2 days (1-4 days). In present study, no major complications were reported in 3 month follow up. Only few minor complications occurred. Seven patients complained of pain at release site beyond 7 days. Ten patients reported erythema and swelling of the finger. Two patients complained of stiffness. All these minor complications were relieved by $2^{\text {nd }}$ or $3^{\text {rd }}$ week. Follow up after one month and 3 months was uneventfuland no recurrence was reported. Eight patients developed triggering in finger other than the one which underwent percutaneous release. These patients were treated as fresh cases. Two patients had simultaneous percutaneous release in two fingers. The average time taken for the procedure was 3 minutes (2-5 minutes). All cases were done as day care procedure and patients were discharged after one hour of observation.

\section{Discussion}

The percutaneous technique is fairly gaining popularity and becoming method of choice for trigger finger release over open release. It is convenient, cost effective with low or no complications such as infection, joint stiffness or weakness, painful scar, bowstringing, nerve damage as encountered in open release. Performed carefully, the complication rate is minimal or even zero. Lange-Riess et $a l^{9}$ in their study of 305 patients, reported complicationsonly in $9(2.95 \%)$ patients and those too temporary complications.

$\mathrm{Ha} \mathrm{KI}$ et $a l^{10}$ reported no complications in their study of 185 patients.

Our results were at par with other reported studies with $100 \%$ success rate with only minor temporary complications. $7(10.29 \%)$ patients had pain and $10(14.70 \%)$ patients had erythema and swelling beyond a week. All these symptoms got resolved by $2^{\text {nd }}$ week. $2(2.94 \%)$ patients had stiffness. Those were the patients who had grade III triggering. They were started on active and passive finger exercises and were followed up weekly. The patients got relieved of the stiffness by $3^{\text {rd }}$ week.

Sahu et $a l^{11}$ reported success rate of $95.6 \%(82.6 \%$ excellent and $13 \%$ good).

Ramy ${ }^{12}$ in his study of 42 patients reported success rate of $95.4 \%$ with complications such as incomplete release of A1 pulley in 3(6.97\%), and superficial flexor tendon laceration in $6(13.95 \%)$ cases. The complete release is to be confirmed by loss of grating sensation and catching. Laceration of the tendon was avoided by withdrawing the needle just out of the tendon into fibroosseous sheath and keeping the bevel of the needle parallel to the tendon.

Will et $a l^{13}$ reported $3 \%$ major complications such as synovial fistula and arthrofibrosis, $28 \%$ minor complications such as erythema, scar tissue, stiffness and loss of range of motion.

Mishra et $a l^{14}$ reported success rate of $95.4 \%$ with no major complications.

Amrani et al $^{15}$ reported 3 recurrences in their study of 63 cases. We encountered no recurrence in in any patient by end of 3 months.

Cadaveric study by Pope and Wolfe ${ }^{16}$ suggests that radial digital nerve was as close as within $2-3 \mathrm{~mm}$ of needle site in percutaneous release in 3 of 5 thumb and 5 of 5 index fingers. Digital nerve injury has been reported in some studies. Ferhat-Guler et $a l^{17}$ reported $5.7 \%$ digital nerve injury. None of our patient had such complication.

The limitations of the study are small sample size and non-availability of complex cases with contracture and fixed flexion deformity (Grade IV).

\section{Conclusion}

Percutaneous release technique of trigger finger is a safe procedure in skilled hands and is justified in every aspect as an alternative to open method in terms of ease of doing, cost effectiveness, lesser invasive, fewer complications, patient satisfaction, lesser morbidity and early resumption of work.

Conflict of Interest: None. 


\section{References}

1. Wolfe SW. Tenosynovitis. In: Green DP, Hotchkiss RN, Pederson WC, Wolfe SW, editors. Green's operative hand surgery. 5th ed. Vol. 2. Philadelphia: Elsevier Churchill Livingstone; 2005. pp. 2137-58.

2. Salim N, Abdullah S, Sapuan J, Haflah NH. Outcome of corticosteroid injection versus physiotherapy in the treat ment of mild trigger fingers. J Hand SurgEur Vol. 2012;37:27-34. [PubMed]

3. Pataradool K, Buranapuntaruk T. Proximal phalanx injection for trigger finger: Randomized controlled trial. Hand Surg. 2011;16:313-7. [PubMed]

4. Yamada K, Masuko T, Iwasaki N. Rupture of the flexor digitorumprofundus tendon after injections of insoluble steroid for a trigger finger. $J$ Hand SurgEur Vol. 2011;36:77-8. [PubMed]

5. Tarbhai K, Hannah S, von Schroeder HP. Trigger finger treatment: A comparison of 2 splint designs. J Hand Surg Am. 2012;37:243-9. [PubMed]

6. Webb J, Stothard J. Cost minimisation using clinic-based treatment for common hand conditions a prospective economic analysis. Ann R CollSurg Engl. 2009;91(2):135-139. [PMC free article] [PubMed]

7. Kerrigan C, Stanwix M. Using Evidence to Minimize the Cost of Trigger Finger Care. J Hand Surg. 2009;34(6):997-1005. [PubMed]

8. East wood DM, Gupta KJ, Johnson DP. Percutaneous release of the trigger finger: an office procedure. J Hand Surg. 1992;17(1):114-117. [PubMed]

9. Lange-Riess D, Schuh R, Hönle W, Schuh A. Long-term results of surgical release of trigger finger and trigger thumb in adults. Arch Orthop Trauma Surg . 2009:16179. [PubMed]

10. Ha KI, Park MJ, Ha CW. Percutaneous release of trigger digits. J Bone Joint Surg Br. 2001;83:75-7.[PubMed]

11. Sahu RL, Gupta P. Experience of percut aneous trigger finger release under local anesthesia in the medical college of Mullana, Ambala, Haryana. Ann Med Sci Res. 2015;4(5):806-809. [PMC free article][PubMed]

12. Diab RA. Percutaneous release of trigger finger. $J$ OrthopSurg (Hong Kong) 2015;23(2):241-242.[PubMed]

13. Will R, Lubahn J. Complications of open trigger finger release. J Hand Surg Am . 2010;35:594-6. [PubMed]

14. Elsayed MM. Percut aneous release of trigger finger. Egypt Orthop J. 2013;48(3):277.

15. Amrani A, Dandane MA, Alami ZF. Percutaneous release of trigger thumb in children: 63 cases. Chir Main. 2011;30:102-4. [PubMed]

16. Pope DF, Wolfe SW. Safety and efficacy of percutaneous trigger finger release. J Hand Surg Am. 1995;20:2803. [PubMed]

17. Guler F, Kose O, Ercan EC, Turan A, Canbora K. Open versus percutaneous release for the treatment of trigger thumb. Orthopedics. 2013;36(10):e1290-e4. [PubMed]

18. Makkouk A, Oetgen M, Swigart C, Dodds S. Trigger finger: etiology, evaluation, and treatment. Curr Rev Musculoskelet Med. 2008;1(2):92-96. [PMC free article] [PubMed] 